\title{
A PROPÓSITO DE UN ÚLTIMO TEXTO DE LUIGI FERRAJOLI. UNA NOTA SOBRE REGLAS, PRINCIPIOS, «SOLUCIONES EN ABSTRACTO»Y «PONDERACIONES EQUITATIVAS»*
}

\author{
Juan Ruiz Manero \\ Universidad de Alicante
}

RESUMEN. En este trabajo, el autor sostiene que la polémica desarrollada en el número precedente de Doxa a propósito del constitucionalismo de FERRAJOL muestra la persistencia de dos desacuerdos entre éste y los autores principialistas: el primero de ellos afecta al entendimiento de las normas constitucionales que atribuyen derechos y el segundo a la ponderación entre principios en relación con casos genéricos. En relación con este último punto, el autor sostiene que la alternativa de FERRAJOLI está constituida por elementos que, o bien directamente no corresponden a la realidad de nuestros sistemas jurídicos (las «soluciones en abstracto»), o bien involucran una toma de posición irracionalista (las «ponderaciones equitativas»).

Palabras clave: FERRAJOLI, principialismo, reglas, principios, «soluciones en abstracto», «ponderación equitativa».

ABSTRACT. In this paper, the author argues that the controversy developed in the previous issue of Doxa about FERRAJOLI's constitutionalism shows the persistence of two disagreements between him and the principialist authors: the first one concerns the understanding of constitutional norms which confer rights and the second the balancing of principles in generic cases. Concerning this last issue, the author argues that FERRAJOLI's alternative comprises elements which simply do not correspond to the reality of our legal systems (the "abstract solutions») or involve taking an irrationalist stance (the «equitable balancings»).

Keywords: FeRRAJOLI, principlism, rules, principles, «abstract solutions», «equitable balancing».

\footnotetext{
* Fecha de recepción: 15 de noviembre de 2012. Fecha de aceptación: 21 de diciembre de 2012.
} 
1.

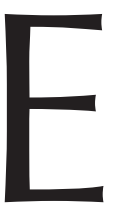
1 trabajo de L. FerRajoli que se publica en este mismo número de Doxa ${ }^{1}$ es una buena muestra de que no siempre los participantes en discusiones de teoría del derecho se limitan, como a propósito de otro debate escribió M. A. Rodilla hace pocos años, a «señalar la posición que cada uno ocupa y marcar territorio». Hay ocasiones, cuando los interlocutores comparten «una cierta tradición de pensamiento» y también, añadiría yo, un cierto cuadro básico de actitudes, en las que resulta posible - como indicó también Rodilla en la misma ocasión- que «la discusión funcione como una vía de aprendizaje» ${ }^{2}$. Es, creo, lo que ha ocurrido con el debate, que centralmente se desarrolló en el número anterior de Doxa, pero que tuvo también otras prolongaciones ${ }^{3}$, generado por el artículo de L. FERRAJOLI «Constitucionalismo principialista y constitucionalismo garantista» ${ }^{4}$. Creo que cualquiera de los participantes en esa discusión concordaría con FERRAJOLI en que la misma ha servido «para eliminar ciertas incomprensiones recíprocas y también para reducir disensos y divergencias debidos, sobre todo en ocasiones, a la diversidad de los aparatos conceptuales utilizados» ${ }^{5}$. Pero hay al menos dos puntos de importancia en los que me parece que subsisten, al menos por lo que a mí respecta, lo que calificaría como «disensos y divergencias» (aunque, pese a lo que indico más adelante, no me animo a descartar del todo que se trate sobre todo de incomprensiones recíprocas tras cuya eliminación aparezca nítido un acuerdo de fondo; si así fuera, y el decurso de la discusión acabara mostrándolo, me alegraría mucho). Estos dos puntos, muy vinculados entre sí, son, por un lado, la manera como entendemos, si como principios o como reglas (y qué entendemos por «principios» y qué por «reglas»), los casos centrales de las normas constitucionales que atribuyen derechos, y, por otro, la necesidad o no de ponderación entre normas (entre principios) en relación con casos genéricos: si no hay manera de evitar tal ponderación o si, por el contrario, podemos solucionar las colisiones entre principios mediante, por un lado, una jerarquización de los mismos que resulte válida al margen de las propiedades que exhiban los casos (esto es, que resulte válida para todos ellos) y, en aquellos supuestos en los que no quepan tales «soluciones en abstracto», mediante la ponderación, no de las normas, sino de las circunstancias individuales de los casos de que se trate (lo que FERRAJOLI llama «ponderación equitativa»).

${ }^{1}$ L. FerRAJOLI, «El constitucionalismo entre principios y reglas» (trad. esp. de P. ANDRÉs IBÁÑ̃̃EZ), en Doxa, núm. 35, 2012.

2 M. Á. RoDILLA, «Imperio de la ley y principios. Presentación de un debate», en F. J. LAPORTA, J. RuIZ MANero y M. Á. Rodilla, Certeza y predecibilidad de las relaciones jurídicas, Madrid, Fundación Coloquio Jurídico Europeo, 2009, 23.

3 Entre ellas, el libro de L. FerRajoli y J. Ruiz Manero, Dos modelos de constitucionalismo. Una conversación, Madrid, Trotta, 2012.

${ }^{4}$ L. FERRAJOLI: «Constitucionalismo principialista y constitucionalismo garantista» (trad. esp. de N. GuZMÁN), en Doxa, núm. 34, 2011. La versión italiana de este artículo se publicó previamente, como «Costituzionalismo principialista e costituzionalismo garantista», en Giurisprudenza costituzionale, 3, 2010.

${ }_{5}^{5}$ L. FERRAJOLI, «El constitucionalismo entre principios y reglas», op. cit., sección 1. 


\section{2.}

Para FERRAJOLI, los supuestos centrales de normas constitucionales que atribuyen derechos pertenecen a la categoría de lo que llama «principios regulativos». Esta categoría viene a ser básicamente coextensiva con la que ATIENZA y yo mismo ${ }^{6}$ denominamos hace tiempo «principios en sentido estricto», pero no es en absoluto, como veremos, cointensiva con ella. Esta convergencia en la extensión y divergencia en la intensión posibilita, creo, plantear sin demasiados malentendidos la discusión, en la medida en que ambas categorías — «principios regulativos» y «principios en sentido estricto»- apuntan básicamente a lo mismo (a las mismas normas) pero ven en ello (en esas normas) características diferentes. Pero esto - la eliminación de malentendidos- se ve, a su vez, dificultado porque los términos que se utilizan para dar cuenta de esas características diferentes —especialmente el término «reglas» y el término «principios»- se usan, por parte de FERRAJOLI, con cargas de sentido que no coinciden con los que las que esos mismos términos tienen en lo que podríamos llamar la visión estándar principialista del problema, visión de la que la reconstrucción realizada por ATIENZA y yo mismo viene a ser una manifestación más. Para dar cuenta adecuadamente de la divergencia relativa a las normas constitucionales que establecen derechos deberemos, pues, tener en cuenta, primero, que el desacuerdo se produce no en relación con la extensión de este concepto (qué normas forman parte de él, qué normas son normas constitucionales que establecen derechos) sino en relación con su intensión (cuáles son las características de estas normas) y, segundo, que para perfilar esa intensión (para nombrar esas características) una y otra parte utilizan los mismos términos (reglas, principios), en sentidos que no coinciden entre sí (o, dicho de otra forma, los conceptos de regla y de principio no son los mismos en los discursos de una y otra parte). Si no se despejan bien estas ambigüedades, el terreno se encuentra abonado, naturalmente, para los pseudoacuerdos y los pseudodesacuerdos.

\section{3.}

De acuerdo con la que he llamado visión estándar del principialismo ${ }^{7}$, el elemento distintivo entre reglas (de acción) y principios (en sentido estricto) ${ }^{8}$ se sitúa básica-

${ }^{6}$ M. Atienza y J. Ruiz Manero, Las piezas del derecho. Teoría de los enunciados jurídicos, Barcelona, Ariel, 1996.

7 Expongo la visión estándar de acuerdo con la versión de la misma que elaboramos Atienza y yo mismo. Cfr. M. Atienza y J. Ruiz MANero, Las piezas del derecho, op. cit., y J. Ruiz MANERO, «Una tipología de las normas constitucionales», en J. Aguiló, M. ATIENZA y J. RuIZ MANERO, Fragmentos para una teoría de la constitución, Madrid, Iustel, 2007. En todo caso, he prescindido de los rasgos que podríamos considerar idiosincrásicos de esta versión para tratar de poner de relieve los rasgos comunes de la orientación principialista, que incluiría, junto con la nuestra, versiones tales como las de ALEXY (R. ALEXY, Teoría de los derechos fundamentales, trad. esp. de E. GARZÓn VALdÉs, Madrid, Centro de Estudios Constitucionales, 1993) o Moreso (J. J. Moreso, «Dos concepciones de la aplicación de las normas de derechos fundamentales», en La Constitución: modelo para armar, Madrid-Barcelona-Buenos Aires, Marcial Pons, 2009). Recientemente, L. CLÉRICO («Sobre "casos” y ponderación. Los modelos de Alexy y Moreso, ¿más similitudes que diferencias?», en Isonomía, núm. 37, octubre de 2012) ha argumentado, en mi opinión convincentemente, en favor de considerar los modelos de ALEXY y MORESO como básicamente equivalentes, a pesar de sus diferencias de presentación.

8 En la versión de ATIENZA y yo mismo se distinguen otros dos tipos de normas regulativas que no entran aquí en consideración. El primero, el de las reglas de fin, porque no está involucrado en absoluto en los temas de 
mente, desde una perspectiva estructural, en el antecedente (condiciones de aplicación o caso, en otras terminologías que consideraré como equivalentes) de ambos tipos de normas. En aquellas normas a las que llamamos reglas, el antecedente está integrado por un conjunto de propiedades que resultan independientes de las razones en pro o en contra de la realización de la acción que figura modalizada deónticamente en el consecuente o solución normativa de la misma norma. Al configurar de esta manera el antecedente, la autoridad normativa pretende que, cuando tal conjunto de propiedades se presente en un caso individual, se genere un deber concluyente en el destinatario de la norma de realizar la acción ordenada en la solución normativa, sin necesidad de que ese mismo destinatario delibere sobre las razones en pro o en contra de ello ${ }^{9}$. Al ser estas reglas el tipo más común de normas jurídicas regulativas, puede pensarse que los ejemplos son innecesarios. Pero, por poner alguno, si uno conduce un vehículo de determinadas características (un automóvil de turismo, por ejemplo) por una carretera de ciertas características (por ejemplo, una autovía) tiene el deber de no superar un cierto límite de velocidad, sin necesidad de deliberación alguna acerca de las razones en pro o en contra de mantenerse dentro de ese límite.

Las cosas son distintas en aquellas normas a las que llamamos principios ${ }^{10}$. Estas normas se caracterizan porque en su antecedente no se contiene otra cosa sino que se dé una oportunidad de realizar la acción modalizada deónticamente en el consecuente. Y esta modalización deóntica no pretende, como en el caso de las reglas, ser concluyente, sino meramente prima facie, por la simple razón de que en muchas ocasiones en que se da la oportunidad de realizar la acción ordenada por un cierto principio, se da también la oportunidad de realizar la acción, incompatible con la anterior, ordenada por otro principio. Siendo así las cosas, los principios no pueden, por su propia configuración, eximir a sus destinatarios de la tarea de determinar si en unas determinadas condiciones o circunstancias lo ordenado por un cierto principio debe, o no, prevalecer sobre lo ordenado por otro principio que resulte concurrente. Los principios no posibilitan, a diferencia de las reglas, eludir la deliberación sobre las razones en

\footnotetext{
la presente discusión. El segundo, el de las directrices, porque aquí no hay nada que valga la pena discutir, porque hay una coincidencia sustancial, en cuanto a su extensión e intensión, entre la caracterización que ATIENZA y yo mismo hacíamos de las normas a las que llamamos directrices con la caracterización ofrecida por FERRAJOLI de las normas a las que denomina principios directivos. Por todo ello en lo sucesivo me referiré a las reglas de acción simplemente como reglas y a los principios en sentido estricto simplemente como principios.

9 Esta pretensión de generar un deber concluyente puede, naturalmente, fracasar. Tal ocurre, por un lado, cuando la regla está mal construida en relación con los principios involucrados en el caso genérico que la misma regula y este defecto de construcción tiene entidad suficiente como para que no prevalezcan frente a él los principios que empujan en pro del seguimiento de reglas y, por otro, cuando, aun estando la regla bien construida en relación con los principios involucrados, se plantea su aplicabilidad a un caso individual, que, aunque de entrada resulta subsumible en la regla, constituye un supuesto situado fuera del alcance o un supuesto de excepción a la misma. No desarrollo estos puntos porque no afectan directamente a la presente polémica con Ferrajoli. Remito, en relación con los mismos, a M. Atienza y J. Ruiz Manero, Ilícitos atípicos, Madrid, Trotta, 2000; M. Atienza y J. Ruiz Manero, «Rules, Principles and Defeasibility», en J. Ferrer Beltrán y G. Battista RatTi, The Logic of Legal Requirements. Essays on Defeasibility, Oxford University Press, 2012; Á. RóDENAS, Los intersticios del derecho. Indeterminación, validez y positivismo jurídico, Madrid, Marcial Pons, 2012.

${ }^{10}$ La distinción entre reglas y principios es una distinción entre lo que podríamos llamar tipos ideales de normas regulativas. No excluye la presencia en nuestros sistemas jurídicos de numerosas normas regulativas que vienen a situarse en una zona de penumbra entre ambos tipos ideales ( $c f r$. sobre ello J. RUIZ MANERO, «Una tipología de las normas constitucionales», op. cit., n. 7, 82 y ss.).
} 
pro o en contra de realizar la acción ordenada por cada uno de ellos frente a las razones en pro o en contra de realizar la acción ordenada por otro principio que resulte concurrente. En tales circunstancias, la ponderación se ve como una operación que desemboca en la formulación de una regla que establece, dadas ciertas circunstancias genéricas, la prevalencia de uno de los principios sobre el otro, es decir, que, dadas esas circunstancias genéricas, debe ser concluyentemente lo ordenado por alguno de los principios en concurrencia. Un ejemplo usual a este respecto es el de la regla elaborada por nuestro tribunal constitucional de acuerdo con la cual, en los supuestos de conflicto entre la libertad de información y el derecho al honor prevalece la primera sólo si la información tiene relevancia pública, es veraz y se comunica sin emplear expresiones injuriosas, mientras que basta con que esté ausente uno de estos tres requisitos para que prevalezca el derecho al honor. Reglas de este tipo valen, se supone, en tanto que un nuevo caso individual no presente una propiedad adicional, no contemplada en la regla, lo suficientemente relevante como para exigir una operación de distinguishing, cuyo resultado sería una nueva regla más fina que la anterior. Las reglas que resultan de operaciones de ponderación o balance entre principios no son, por tanto, como no lo es ninguna regla, absolutamente estables, pues siempre es posible que la regla aparezca, frente a casos que presentan combinaciones no previstas de propiedades, como supraincluyente o, lo que es lo mismo, que esos mismos casos constituyan otros tantos supuestos de laguna axiológica. Pero esas mismas reglas son, a su vez, relativamente estables, pues valen, como se ha dicho, en tanto que un caso individual no presente una propiedad no contemplada en la regla cuya relevancia exija una operación de distinguishing. Y en tal caso el resultado es, como también se ha dicho, una nueva regla más fina. Que será, a su vez, relativamente estable en el sentido recién precisado.

Pues bien, para la visión que hemos convenido en llamar principialista, los casos centrales de normas constitucionales que establecen derechos están configurados, en constituciones como las nuestras, en forma de principios y no de reglas y hay buenas razones para entender que deben estar configuradas así. Razones que remiten a la pretensión de duración larga de los textos constitucionales, a las dificultades para su modificación, a la necesidad de que los mismos constituyan, durante un amplio horizonte temporal, el terreno común compartido para la deliberación pública. Pues para ello resulta conveniente que los textos constitucionales no cierren la deliberación respecto al alcance y a la articulación recíproca entre los derechos que ellos mismos confieren. El no cierre de la deliberación respecto al alcance de cada uno de los derechos y respecto a la articulación recíproca entre ellos se logra, primero, mediante el uso de términos fuertemente valorativos para caracterizar los derechos y, segundo, no pretendiendo anticipar - lo que resultaría una pretensión infundada, pues el constituyente no es, obviamente, omnisciente - todas las posibles combinaciones de propiedades - y la relevancia de cada una de ellas- que puedan presentar los casos futuros en que haya una oportunidad de realizar el contenido de más de un derecho constitucionalmente conferido, de un derecho fundamental.

\section{4.}

Pues bien: para FERRAJOLI las normas constitucionales que confieren derechos fundamentales deben ser entendidas como reglas y, a la vez, como principios. Pero 
los términos regla y principio designan, en la terminología de FERRAJOLI y como ya se indicaba, conceptos distintos de los designados por esos términos en lo que vengo llamando la visión estándar del principialismo. FERRAJOLI entiende por reglas y, más precisamente, por reglas deónticas, «todas y sólo las normas de las que cabe configurar los actos que son su observancia o su inobservancia» ${ }^{11}$. Obsérvese que el concepto de regla de FERRAJOLI no remite, como ocurre en la visión principialista estándar, a algún rasgo del antecedente de las normas así denominadas, sino a un rasgo del consecuente de las mismas. Pues bien: resulta claro que las normas constitucionales que establecen derechos fundamentales pueden ser observadas o inobservadas, cumplidas o violadas. Y de ahí que, de acuerdo con este concepto de regla deóntica, la conclusión de FERRAJOLI sea inobjetable: «Los derechos fundamentales son reglas deónticas, es decir, figuras deónticas de carácter universal cuyos temas-objeto consisten en posibles actos o comportamientos que son su observancia o inobservancia. En cuanto tales, los mismos pueden ser unas veces respetados y otras violados [...]; es por la posibilidad de sus violaciones, por acción o por omisión, por lo que las normas que los establecen son caracterizables como reglas deónticas» ${ }^{12}$. Hasta aquí, y si se acepta la definición de reglas deónticas propuesta por FERRAJOLI, ningún problema: en la afirmación de que las normas que establecen derechos fundamentales pueden ser observadas o inobservadas no puede haber, naturalmente, más que acuerdo. El problema se sitúa en la definición de reglas deónticas propuesta por FERRAJOLI. Por lo siguiente: porque de acuerdo con esta definición de reglas deónticas, que atiende exclusivamente al consecuente de las normas, no puede darse cuenta de la diferencia de la que la visión principialista trata de dar cuenta mediante la distinción entre reglas y principios, diferencia que afecta básicamente no al consecuente de las normas (en cuanto al consecuente, tanto en reglas como en principios se encontraría modalizada deónticamente la realización de una acción) sino a su antecedente, elemento que queda por completo eludido en la definición de FERRAJOLI. Ciertamente, de acuerdo con la visión principialista hay una diferencia en el consecuente de reglas y principios: las primeras contienen una modalización deóntica que pretende ser concluyente, mientras que la modalización deóntica de los segundos es sólo prima facie, modalización deóntica que se transforma en concluyente cuando la ponderación ha desembocado en la elaboración de una regla que determina la prevalencia para ciertos casos genéricos del principio de que se trate frente a otros que resulten concurrentes. Pero no cabe duda tampoco de que, si es que debiéramos partir de la definición de FERRAJOLI, aquello de lo que pretende darse cuenta en la visión estándar del principialismo mediante la distinción entre reglas y principios, podría recuperarse de otra manera: dentro de las reglas deónticas podría distinguirse entre reglas deónticas de antecedente abierto, cuyo consecuente contendría una modalización deóntica prima facie (lo que la visión estándar llama principios) y reglas deónticas de antecedente cerrado, cuyo consecuente contendría una modalización deóntica que se pretende concluyente (lo que la visión estándar llama simplemente reglas). Si modificando la terminología se pudiera sellar la paz con FERRAJOLI, nadie habría más pacifista que yo, y no tanto por una preferencia caracteriológica, que tengo, por la ausencia de conflicto, sino porque, en tal caso, el conflicto obedecería a un mero pseudodesacuerdo: la diferente terminología impediría ver la existencia de un acuerdo de fondo. Pero

\footnotetext{
11 L. FERRAJOLI, «El constitucionalismo entre principios y reglas», op. cit., sección 4.

12 Id., sección 5 .
} 
me temo que, lamentablemente, las cosas no son así, que hay un desacuerdo genuino, y que no es, por tanto, tan fácil llegar a la paz.

Más adelante recorreré el camino que desemboca, creo que inevitablemente, en tan melancólica conclusión. Pero vuelvo ahora a la consideración de FERRAJOLI de que las normas fundamentales que establecen derechos fundamentales son «principios regulativos», o sea, normas que son a la vez reglas y principios. Ya hemos visto en qué sentido tales normas son, de acuerdo con FERRAJOLI, reglas. Veamos ahora en qué sentido son, también de acuerdo con FERRAJOLI, principios. El sentido en que tales normas son principios afecta exclusivamente a la forma en que aparecen expresadas en los textos constitucionales, esto es, a aparecer bajo la forma de normas atributivas de derechos y no de normas que imponen obligaciones y prohibiciones. Esto no es irrelevante porque apunta, dice FERRAJOLI, «los derechos expresan de manera más directa los valores que informan el ordenamiento de lo que lo hacen las reglas construidas en términos de obligaciones y prohibiciones» ${ }^{13}$. Pero las normas que atribuyen derechos («principios», en la terminología de FERRAJOLI) y las normas que imponen obligaciones y prohibiciones («reglas», en la misma terminología) tienen, según reitera el mismo FERRAJOLI, exactamente el mismo alcance normativo, las mismas consecuencias en cuanto a la regulación de la conducta y, por ello, la diferencia entre «reglas» y «principios regulativos» es a la postre, de acuerdo con FERRAJOLI, poco más que de estilo redaccional. Pues los principios regulativos «se comportan, como resulta evidente sobre todo frente a sus violaciones, exactamente como las reglas» ${ }^{14}$.

\section{5.}

$\mathrm{Si}$, aun a riesgo de ser reiterativos, tratamos, ahora, de resumir las diferencias entre FERRAJOLI y la visión estándar del principialismo en cuanto al instrumental conceptual empleado en el respecto que nos ocupa, éstas vendrían a ser las siguientes.

En la visión principialista estándar, i) la distinción entre reglas y principios parte de la diferente manera como aparece configurado el antecedente de uno y otro tipo de normas: mediante un conjunto de propiedades independientes de las razones para realizar la acción ordenada en el consecuente en el caso de las reglas; exigiendo sólo que se dé una oportunidad de realizar la acción ordenada en el consecuente en el caso de los principios; ii) en virtud de esa diferente configuración del antecedente, en el caso de las reglas se pretende que la acción ordenada en el consecuente resulta concluyentemente debida siempre que se dé el conjunto de propiedades que figura en el antecedente, mientras que en el caso de los principios la acción ordenada en el consecuente pretende ser debida únicamente prima facie, dado que siempre cabe que, junto con la oportunidad de realizar tal acción, se dé asimismo la oportunidad de realizar otra acción ordenada por otro principio, acción que resulte incompatible con la ordenada por el principio bajo consideración, y iii) en virtud de lo anterior, para transformar el debe prima facie contenido en el consecuente de un principio en un debe concluyente es preciso ponderar ese principio con otros principios que resulten

\footnotetext{
13 Dos modelos de constitucionalismo, op. cit., p. 57.

14 Ibid., p. 94.
} 
eventualmente concurrentes y el resultado de tal ponderación es una regla que determina la prevalencia de uno de esos principios en relación con ciertos casos genéricos o conjuntos de propiedades.

Adviértase que, para la visión principialista, el que la norma aparezca formulada en términos de atribución de derechos o en términos de imposición de deberes es, por una parte, importante en términos de relaciones de justificación: si los poderes públicos tienen, por ejemplo, el deber de abstenerse de interferir en los actos de ejercicio de la libertad de expresión, tal deber encuentra su justificación en que los individuos tienen un derecho a la libertad de expresión; no tendría ningún sentido, en cambio, decir que se justifica la adscripción de un derecho individual a la libertad de expresión en que los poderes públicos tienen prohibida la interferencia con los actos de ejercicio del mismo ${ }^{15}$. Pero, por otra parte, para la visión principialista, la formulación en términos de derechos o en términos de deberes correlativos es irrelevante para el carácter de principio de una determinada norma. Tan principio es una norma que adscriba o reconozca un derecho individual a la libertad de expresión, siempre que no precise en qué casos ese derecho prevalece frente a otros que resulten concurrentes, como una norma que imponga un deber de abstenerse de interferir en los actos de ejercicio de la libertad de expresión, siempre que no precise en qué casos ese deber prevalece frente a otros que resulten concurrentes.

Pero es precisamente este punto (la formulación en términos de derechos o de deberes correlativos), que resulta irrelevante, de acuerdo con la visión principialista, para caracterizar una norma como regla o como principio, el que en la construcción de FERRAJOLI aparece como determinante de la distinción entre reglas y principios. En efecto, para FERRAJOLI: i) los «principios regulativos» son a la vez reglas y principios; son reglas por cuanto ordenan acciones de forma tal que podemos determinar los actos que constituyen su observancia o su inobservancia; son principios por cuanto aparecen formulados expresamente en términos atributivos de derechos y no en términos de imposición de los deberes correlativos; ii) ambas formulaciones —en términos de derechos o en términos de deberes- son normativamente equivalentes. La formulación en términos de derechos pone en primer plano la razón de la imposición de deberes - y ello resulta preferible en muchos contextos-, pero una y otra formulación tienen exactamente los mismos efectos normativos, a través de una y de otra formulación se regula la conducta exactamente de la misma forma y con los mismos alcances, y iii) por ello, los «principios regulativos» no requieren ninguna clase de ponderación con otros principios concurrentes, como operación previa a su aplicación, sino que, al igual que todas las demás reglas, exigen, sin más, ser directamente aplicados.

A partir de esta contraposición podría aventurarse que no tiene por qué haber un desacuerdo sustantivo entre FERRAJOLI y los partidarios de la visión estándar del principialismo; sencillamente FERRAJOLI llama «principios» y «reglas» a cosas distin-

15 Tesis con la que concuerda FerRAjOli. $C f r$ r. el texto citado en n. 13 y también en «El constitucionalismo entre reglas y principios», la siguiente afirmación: la formulación en términos de derechos y no de los correlativos deberes es la forma en que «las constituciones expresan directamente los fines y las opciones éticopolíticas que el ordenamiento quiere perseguir», y, de ahí, la «llamada función "normogenética" [de las normas así formuladas], es decir, su aptitud para justificar una pluralidad de reglas, sean explícitas o implícitas» («El constitucionalismo entre reglas y principios», sec. 4). 
tas de las que los principialistas entienden por tales. Y, como se ha sugerido antes, la distinción sustantiva de la que el principialismo trata de dar cuenta en términos de «reglas» y «principios», podría ser reflejada, de acuerdo con las categorías de FERRAJOLI, distinguiendo entre «reglas (o principios) de antecedente abierto» (lo que la visión estándar llama «principios») y «reglas (o principios) de antecedente cerrado» (lo que la visión estándar llama «reglas»). Pero, lamentablemente para la tendencia al irenismo que algunos tenemos, esta última distinción no cabe en FERRAJOLI. Y no cabe porque no hay, en su construcción, espacio para normas con antecedente abierto. $Y$, puesto que no caben normas con antecedente abierto, no es precisa ponderación alguna entre normas. Las colisiones entre principios pueden ser solucionadas en gran parte, utilizando la propia terminología de FERRAJOLI, «en abstracto», esto es, mediante una jerarquización de tales principios que valdría para todo caso posible. Y allá donde no alcanzan las «soluciones en abstracto», la única ponderación admisible tiene lugar, a juicio de FERRAJOLI, no entre normas y en relación con casos genéricos, sino entre los hechos irreductiblemente singulares propios de cada caso individual. Se trata de lo que FERRAJOLI llama «ponderación equitativa». Es en relación con estos dos puntos — las «soluciones en abstracto» y la «ponderación equitativa»- donde la divergencia entre la visión principialista y la ferrajoliana me parece insalvable. Veámoslo.

6.

FERRAJOLI ha insistido una y otra vez ${ }^{16}$ en la tesis de que, en muy amplia medida, los diversos principios pueden y deben ser jerarquizados de forma tal que sus relaciones de prevalencia queden preestablecidas para todo caso posible (y esta tesis le ha sido criticada, asimismo, una y otra vez ${ }^{17}$. Me limitaré aquí a prestar atención a la última formulación de esta tesis, la que encontramos en «El constitucionalismo entre principios y reglas». Leemos en este trabajo que «gran parte de los conflictos entre derechos, imaginables en abstracto, no son conflictos en sentido propio que requieran ponderaciones. Se trata más bien de límites impuestos por alguno de ellos al ejercicio de otros, implícitos en la estructura lógica de los mismos principios o derechos, a veces explicitados por las propias normas constitucionales, y en todo caso reconocibles en general y en abstracto en sede de interpretación judicial o doctrinal [...]. Se trata de límites de carácter lógico y conceptual [...] de relaciones entre tipos de derechos reconocidos en el plano teórico o doctrinal de una vez para siempre» ${ }^{18}$.

16 L. FerRajoli, «Los fundamentos de los derechos fundamentales», en L. FerRajOli y otros, Los fundamentos de los derechos fundamentales, ed. de A. DE CABO y G. PisARello, Madrid, Trotta, 2001, 339 y ss.; L. FERRAJoli, Principia iuris. Teoria del diritto e della democracia, Bari, Laterza, 2007, vol. 1: Teoria del diritto, 754 y ss., vol. 2: Teoria della democracia, 72-73; «Constitucionalismo principialista y constitucionalismo garantista», op. cit., 44 y ss.

17 Destacaré, entre estas críticas, las debidas a P. COMAnDuccI, «Problemas de compatibilidad entre derechos fundamentales», en M. CARBONELL y P. SALAZAR (eds.), Garantismo. Estudios sobre el pensamiento jurídico de Luigi Ferrajoli, Madrid, UNAM-Trotta, 2005, y a J. J. MORESO, «Sobre los conflictos entre derechos», en Garantismo, op. cit. (publicado también con el título de «Derechos y constitucionalismo sin conflictos», en La constitución: modelo para armar, Madrid-Barcelona-Buenos Aires, Marcial Pons, 2009). Coincido ampliamente, como muestra lo que sigue, con este último texto.

18 «El constitucionalismo entre principios y reglas», sección 6 . 
Dos son los límites que cabe distinguir a este respecto. Un primer límite deriva de que, dice FERRAJOLI, «los derechos fundamentales consistentes en meras inmunidades, esto es, solamente en expectativas pasivas y no también en modalidades activas, o sea, en facultades y poderes [...], puesto que no comportan ningún acto como su ejercicio, están tendencialmente en el vértice de la jerarquía» ${ }^{19}$. El ejemplo que pone FERRAJOLI es que «nunca se ha dudado de que la libertad de manifestación del pensamiento tenga un límite en la dignidad de la persona, y por eso su inmunidad frente a difamaciones, injurias o calumnias» ${ }^{20}$.

El segundo límite, que FERRAJOLI considera «de bastante mayor importancia», «mira a las relaciones entre todos los derechos fundamentales, incluidos los derechos sociales y los derechos de libertad [...] y los derechos fundamentales de autonomía civil, que son además poderes, dado que su ejercicio consiste en actos jurídicos productores de efectos en la esfera jurídica de otros [...] El ejercicio de los segundos [...], los actos que son su ejercicio, como por ejemplo los de carácter contractual, se hallan, en la estructura en grados del ordenamiento, en un nivel más bajo que el constitucional, al que pertenecen todos los derechos fundamentales, ninguno de los cuales puede ser por eso derogado por ellos» ${ }^{21}$.

De manera, pues, que tenemos, según FERRAJOLI, tres grupos jerarquizados de derechos fundamentales: en primer lugar, y en el vértice, «las simples inmunidades fundamentales», «supraordenadas al ejercicio de todos los demás»; en segundo lugar, «los derechos activos de libertad» y los derechos sociales, subordinados unos y otros a las inmunidades; en tercer lugar, los derechos-poder de autonomía, situados en el nivel más bajo, porque su ejercicio está subordinado «al respeto de todos los demás», esto es, tanto de los del primer grupo, como de los del segundo grupo.

Pues bien, puede observarse que es, la de FERRAJOLI, una bien limpia construcción que, de poder sostenerse, eliminaría también limpiamente cualquier necesidad de ponderación en un buen número de supuestos de colisión entre derechos fundamentales. Pero, por desgracia para FERRAJOLI, tanta limpieza no se halla en el mundo real de nuestros sistemas constitucionales. Empecemos por el primer límite, aquel de acuerdo con el cual las inmunidades fundamentales están supraordenadas a cualquier otro derecho fundamental. El ejemplo que pone FERRAJOLI es, como se acaba de indicar, el de la «dignidad de la persona», que constituiría un límite infranqueable para cualquier otro derecho fundamental. Y, aparentemente, si nos fijamos en lo que podríamos llamar la «gramática superficial» de la dignidad, FERRAJOLI parece tener razón. Pues, en efecto, no parece que pueda hablarse de cosas tales como «trato justificado no respetuoso de la dignidad humana», porque no puede predicarse de la dignidad humana que ésta deba ceder frente a otros principios constitucionales. De la dignidad humana no podemos hablar de modo análogo a como hablamos, por ejemplo, de la libertad de expresión, en relación con la cual podemos decir cosas tales como que tal

19 Id., sección 6. Podría pensarse que el uso del adverbio «tendencialmente» indica cierta cautela, alguna suerte de admisión de que las cosas pudieran no ser así en todos los casos. Pero, a continuación, FERRAJOLI desarrolla su tesis, como ha venido haciendo siempre, sin referencia alguna a eventuales excepciones. Qué pueda querer decir «tendencialmente», queda, pues, inexplicado.

${ }^{20} I d$., sección 6.

${ }^{21} I d$. 
acción fue un supuesto de «interferencia justificada en la libertad de expresión» para proteger, por ejemplo, el derecho al honor o de que en tal otro caso, por el contrario, el derecho al honor cedió justificadamente frente a la libertad de expresión. La dignidad humana no parece ceder en ningún supuesto frente a ningún otro principio que pudiera resultar concurrente. Pero ello no significa, contra lo que pretende FERRAJOLI, que el respeto a la dignidad, como guía de la conducta, esté supraordenado a los demás principios constitucionales. Porque en constituciones como las nuestras, el respeto a la dignidad humana no tiene, como guía de la conducta, más alcance que el del respeto a los diversos derechos fundamentales que, según la fórmula del art. 10 de la Constitución española, resultan «inherentes» a la misma y que concretan las exigencias que se derivan de ella. Pero si los derechos fundamentales son presentados, todos ellos, como «inherentes» a la dignidad de la persona, la «dignidad de la persona» no da lugar, a su vez, a ningún derecho fundamental específico: no hay, en nuestra Constitución, ningún derecho específico a la dignidad. Ello explica que no quepa recurso de amparo frente a una eventual violación de la dignidad humana que no sea, al tiempo, violación de alguno de los derechos fundamentales que resultan «inherentes» a ella. Y esto plantea, a su vez, el problema de la virtualidad normativa del principio de dignidad en una Constitución como la española. Y es aquí donde encontramos la «gramática profunda», y ya no superficial, del principio de dignidad. Lo esencial de esa «gramática profunda» se halla, a mi juicio, en lo siguiente: si distinguimos en los principios constitucionales, y en las normas jurídicas en general, una vertiente justifcativa, por un lado, y una vertiente de guía de la conducta, por otro, la virtualidad justificativa del principio de dignidad resulta indudable, y ello se manifiesta, por ejemplo, en las apelaciones a la dignidad que encontramos en la jurisprudencia constitucional en relación con la justificación de determinados límites de los derechos fundamentales o de determinados límites de la actividad legítima de los poderes públicos. Pero la vertiente de guía de conducta de la dignidad parece reconducirse por completo a los diversos derechos fundamentales «inherentes» a ella, en los que se concreta. Si esto es así, tendríamos que admitir que la dignidad es un principio que, aunque desde el punto de vista de su virtualidad justificativa se sitúa en el nivel (justificativo) más alto de un sistema jurídico como el nuestro, desde el punto de vista de su vertiente de guía de la conducta, lo característico del mismo es que incorpora un concepto valorativo ligero que no guía la conducta sino a través de aquellos otros conceptos, más densos, que concretan sus exigencias, y que aparecen en la formulación de cada uno de los diversos derechos fundamentales ${ }^{22}$. Y todos los derechos fundamentales, en cuya formulación aparecen estos conceptos más densos, ceden, en determinados supuestos, frente a otros derechos fundamentales que resulten concurrentes. Y en relación con ello, no son una excepción aquellos derechos fundamentales que parecen mantener una conexión más directa con la idea de dignidad, tales como el derecho al honor o a la intimidad personal que, en determinados supuestos, prevalecen frente a la libertad de expresión y, en otros, ceden frente a ella.

${ }^{22}$ Las cosas no son distintas en relación con la Ley Fundamental de Bonn, pese a la mucha mayor presencia del concepto de dignidad humana en la jurisprudencia constitucional alemana. Tampoco aquí hay un derecho fundamental específico a la dignidad, sino que ésta se sitúa en la base justificativa de los diversos derechos fundamentales y constituye, como tal, un criterio interpretativo de las normas constitucionales que se refieren a esos mismos derechos. 
El segundo de los límites señalados por FERRAJOLI apunta a los derechos-poderes de autonomía civil, cuyo ejercicio estaría, en su opinión, subordinado a todos los demás derechos fundamentales. Esto comporta una versión particularmente fuerte de la llamada «eficacia horizontal de los derechos fundamentales», de su fuerza normativa frente a los particulares, que no creo se corresponda con la realidad de nuestros sistemas jurídicos. Pensemos, por ejemplo, en el derecho-poder de otorgar testamento. Todos tenemos, frente a los poderes públicos, el derecho a no ser discriminados por nuestras creencias religiosas, pero ¿lo tenemos también, en la misma medida, frente a actos de ejercicio de autonomía privada, tales como el de otorgar testamento?; ¿debería anularse un testamento en la parte, perteneciente al tercio de libre disposición, en que contuviera un legado destinado a promover las creencias propias de una determinada congregación religiosa?; ¿̇o en la parte, perteneciente al tercio de mejora, en que dispusiera que sea mejor tratado, y por esa razón, aquel hijo que comparte las creencias religiosas del padre testador? No parece que sea así como son generalmente interpretadas nuestras disposiciones constitucionales referidas a la prohibición de discriminación por razones religiosas (o, tanto da en este contexto, al derecho a no ser discriminado por razones religiosas) y el que no se interpreten así parece obedecer a que generalmente entendemos que el alcance de tal prohibición es bastante menor en relación con el ejercicio de poderes de autonomía privada de lo que lo es en relación con el ejercicio de potestades públicas. Ciertamente, podría decirse que el que un ejercicio de un poder privado introduzca un trato diferente por razones religiosas no constituye discriminación, en el sentido relevante, mientras que sí lo constituiría ese mismo trato diferente si fuera introducido en el ejercicio de alguna potestad pública. Pero esto no pasa de ser otra manera (creo que algo más confusa) de decir lo mismo: a saber, que el derecho a la no discriminación por razones religiosas cede, en el ejercicio de poderes privados, frente a la autonomía personal, que se manifiesta en el ejercicio de tales poderes privados, en un amplio rango de supuestos y que no ocurre algo semejante frente a la persecución de intereses colectivos llevada a cabo mediante el ejercicio de potestades públicas, ámbito en que la prohibición de discriminación por razones religiosas tiene un alcance incomparablemente mayor.

\section{7.}

En todo caso, las «soluciones en abstracto» que, a juicio de FERRAJOLI, evitan la necesidad de ponderar en un buen número de supuestos que aparecen, de entrada, como de colisión entre derechos, no pueden ser aplicadas a todos los supuestos de tales colisiones. Hay, en particular, supuestos de colisión entre derechos de libertad para los que FERRAJOLI admite que no disponemos de «soluciones en abstracto» predispuestas. En tales supuestos, en su opinión, la solución ha de venir, no de la ponderación entre normas (entre principios) propugnada por los principialistas, sino de la ponderación entre las circunstancias de los casos individuales de que se trate (en su terminología, de la «ponderación equitativa»). Partamos de un pasaje en el que FERRAJOLI da cuenta, por una parte, de cómo, en su opinión, entienden los principialistas la ponderación y, por otra, de cómo tal ponderación debe, también en su opinión, ser entendida. Dice FERRAJOLI lo siguiente: «El derecho vigente es la única lengua de que disponen los jue- 
ces para nombrar los hechos que enjuician: como hurto o apropiación indebida, como ejercicio de la libertad de prensa o como difamación, no porque pesen el significado de estas palabras - es decir, las normas sobre el hurto, la apropiación indebida, la libertad de prensa y sobre la dignidad de las personas (más de lo que pesamos, hablando, las palabras "silla" o "butaca") — sino porque valoran (o, si se quiere, pesan) las particularidades singulares de los hechos enjuiciados que los hacen identificables y más fundadamente designables como hurto, apropiación indebida, legítimo ejercicio de la libertad de prensa o indebida difamación lesiva de la dignidad personal» ${ }^{23}$.

Pues bien: creo que lo primero que debe decirse a propósito de este texto es que FERRAJOLI presenta la ponderación entre principios defendida por los principialistas en unos términos en los que me parece muy dudoso que alguno de éstos se reconozca: nadie ha sostenido, que yo sepa, que haya que ponderar, como a juicio de FERRAJOLI defienden los principialistas, el «peso» relativo del «significado de las palabras». Ni siquiera parece que hablar de «pesar significados» tenga algún sentido (yo, al menos, me confieso completamente incapaz de encontrar en tan extraña expresión algún significado que yo pueda entender). Lo que los principialistas dicen que hay que ponderar es el peso de las razones que, en uno y otro conjunto de circunstancias genéricas, respaldan a los principios en conflicto. Lo explicaré con un ejemplo, que de tan habitual pudiera resultar hasta tedioso: supongamos un conflicto entre el derecho a la intimidad y la libertad de información del tipo de si puede legítimamente divulgarse algo referido al historial de tratamientos psiquiátricos recibidos por un candidato, digamos, a la presidencia del gobierno. Frente a un caso semejante, y suponiendo que no haya una regla predispuesta que determine la prevalencia de alguno de los derechos en conflicto, ponderamos, de acuerdo con los principialistas, las razones en pro del derecho a la intimidad frente a las razones en pro de la libertad de información en relación con las circunstancias relevantes del caso, entendiendo que el resultado de la ponderación es siempre una regla. Una regla, por ejemplo, que estipule que, en el caso de los candidatos a la presidencia del gobierno, y de su historial psiquiátrico, prevalece la libertad de información sobre el derecho a la intimidad (por la importancia que tiene el ser una persona psicológicamente equilibrada para tomar las decisiones, con frecuencia graves y urgentes, que corresponde tomar al presidente del gobierno, etc.). Naturalmente, esta regla no predetermina la prevalencia de la libertad de información sobre el derecho a la intimidad en cualquier otro caso posible de colisión entre ambas: en un caso, por ejemplo, en que se trate del historial psiquiátrico de un candidato a una alcaldía y no a la presidencia del gobierno (aquí podría quizás sostenerse que para las decisiones que toma un alcalde no es tan importante que padezca algún trastorno psicológico, etc.) o bien porque, aun tratándose del candidato a la presidencia del gobierno, no se trata ya del historial psiquiátrico, sino, digamos, del dermatológico (que no afecta para nada a la capacidad de tomar decisiones difíciles, etc.). Pero nos estamos moviendo siempre

23 «El constitucionalismo entre principios y reglas», apartado 8. En el mismo sentido, en «Constitucionalismo principialista y constitucionalismo garantista», op. cit.: «La ponderación [...] tiene por objeto no las normas a aplicar, sino, antes bien, las circunstancias de hecho previstas por las mismas a los fines de calificar jurídicamente y connotar equitativamente el caso sometido al juicio» (47-48), y también en Dos modelos de constitucionalismo, op. cit.: «Si queremos hablar de “ponderación”, me parece más simple y correcto [...] afirmar que el objeto de la ponderación son, caso por caso, las connotaciones singulares e irrepetibles de los hechos y de las situaciones juzgadas, que son siempre distintas aun cuando subsumibles en las mismas normas» (83). 
al nivel de las circunstancias genéricas. Si un caso no presenta circunstancias genéricas relevantes distintas de las de otro caso, ambos deben recibir la misma solución, pues son subsumibles en la misma regla.

Sin embargo, de acuerdo con FERRAJOli, lo que debemos ponderar no es el peso de las razones que respaldan a cada uno de los derechos en conflicto en relación con las circunstancias genéricas del caso, sino las circunstancias individuales de ese mismo caso, «las particularidades singulares de los hechos enjuiciados». Confieso que «ponderar particularidades singulares de los hechos» me parece, tomada literalmente, una expresión tan incomprensible como «ponderar significados de palabras». Pero atenerse a la literalidad sería, sin duda, injusto con FERRAJOLI. Lo que claramente quiere decir, me parece, es que debemos ponderar el peso de las razones que respaldan a cada uno de los derechos en conflicto en relación con las particularidades singulares de los hechos enjuiciados. Pero, en mi opinión, si estas «particularidades singulares» no las vemos como instancias de propiedades genéricas, no tenemos manera de referirnos a ellas en términos comunicables a los demás, pues nuestro lenguaje no dispone de nombres propios para designar esas «particularidades singulares», y ni siquiera tenemos otra forma de captarlas que no sea alguna suerte de intuición no comunicable y no controlable intersubjetivamente ${ }^{24}$. La solución que propugnemos, pues, no podrá presentarse en términos que se pretendan justificados, sino que aparecerá, necesariamente, como arbitraria. Y ello porque nuestra idea de justificación implica la idea de tratar de forma semejante los casos semejantes, o, lo que es lo mismo, la idea de que los casos que exhiban las mismas propiedades genéricas relevantes deben recibir una solución semejante. Y ello, en el caso de las colisiones entre principios, implica la necesidad de ponderar las razones que respaldan a cada uno de ellos en relación con unos u otros conjuntos de circunstancias genéricas. La aversión a la ponderación así entendida parece haber abocado a FERRAJOLI, a su pesar, a una suerte de irracionalismo bien alejado de los rasgos centrales de su construcción, de esos rasgos centrales que hacen que muchos la consideremos, pese a todas las críticas a las que nos parece acreedora, como una de las contribuciones más estimables a la teoría del derecho de los últimos decenios.

24 Naturalmente, siempre tenemos la posibilidad de encontrar en el caso «particularidades singulares» del mismo que no sean reconducibles a alguna combinación de propiedades genéricas. Tal ocurre si empleamos en nuestra descripción del mismo el nombre propio o alguna descripción definida de la persona o personas involucradas. Pero considerar como propiedad relevante de un caso la identidad de la persona o personas involucradas en él significaría, obviamente, el abandono sin disimulos de la pretensión de universalización que es parte constitutiva de nuestra idea de justificación. 